\title{
An improved control for MPPT based on FL-PSo to minimize oscillation in photovoltaic system
}

\author{
Aji Akbar Firdaus', Riky Tri Yunardi², Eva Inaiyah Agustin ${ }^{3}$, Sisca D. N. Nahdliyah ${ }^{4}$, \\ Teguh Aryo Nugroho 5 \\ 1,2,3,4 Department of Engineering, Faculty of Vocational, Universitas Airlangga, Indonesia \\ ${ }^{5}$ Department of Electrical Engineering, Universitas Pertamina, Indonesia
}

\section{Article Info \\ Article history: \\ Keywords: \\ Boost converter \\ FL-PSO \\ MPPT \\ Oscillation \\ Photovoltaic}

Received Sep 4, 2019

Revised Nov 22, 2019

Accepted Jan 13, 2020

\begin{abstract}
Photovoltaic (PV) is a source of electrical energy derived from solar energy and has a poor level of efficiency. This efficiency is influenced by PV condition, weather, and equipments like Maximum Power Point Tracking (MPPT). MPPT control is widely used to improve PV efficiency because MPPT can produce optimal power in various weather conditions. In this paper, MPPT control is performed using the Fuzzy Logic-Particle Swarm Optimization (FL-PSO) method. This FL-PSO is used to get the Maximum Power Point (MPP) and minimize the output power oscillation from PV. From the simulation results using FL-PSO, the values of voltage, and output power from the boost converter are $183.6 \mathrm{~V}$, and $637.7 \mathrm{~W}$, respectively. The ripple of output power from PV with FL-PSO is $69.5 \mathrm{~W}$. Then, the time required by FL-PSO reaches MPP is $0.354 \mathrm{~s}$. Compared with MPPT control based on the PSO method, the MPPT technique using FL-PSO indicates better performance and faster than the PSO.
\end{abstract}

This is an open access article under the $\underline{C C B Y-S A}$ license.

\section{Corresponding Author:}

Aji Akbar Firdaus,

Department of Engineering,

Universitas Airlangga,

Gubeng, Surabaya 60286, Indonesia.

Email: aa.firdaus@vokasi.unair.ac.id

\section{INTRODUCTION}

There are various types of renewable energy that coming to replace fossil-fueled plants such as photovoltaic (PV) [1] and wind turbine [2]. Lately, PV gets much attention because PV uses solar energy that holds very abundant availability to generate electricity while having environmental benefits and low maintenance costs $[3,4]$. However, the advantages of PV still cannot be highlighted compared to its shortcomings that the investment costs of PV are expensive and the PV power efficiency is low. The efficiency of PV is influenced by many causes such as PV condition, and weather like solar radiation, and temperature [4]. Besides the reasons above, the presence of MPPT technique also affects the power generated of the PV system. Research currently developing MPPT techniques can be implemented to optimize the power generated by PV systems such as Incremental Conductance (IC) [5], Perturb and Observe (P\&O) [6-8], and Hill Climbing (HC) [9]. However, besides being able to produce better output, P \& O and $\mathrm{HC}$ can produce bad oscillations and speed for the equipment while IC method can reduce oscillation, besides that, this method is susceptible to significant irradiance changes. One of the ways that can be used to overcome the problem of oscillation is using artificial intelligence.

Several artificial intelligence methods were developed to overcome oscillation problems and tracking efficiency. As the examples are Neural Network (NN), Particle Swarm Optimization (PSO), Firefly, 
and Grey Wolf Optimization (GWO). NN constraints [10,11] are large amounts of data when training and flexibility of Fuzzy Logic Controller (FLC) [12] are limited due to the characteristics of non-linear solar modules. PSO [13], Firefly [14] and GWO [15] have widely used in the engineering field. In this paper, the Fuzzy Logic-Particle Swarm Optimization (FL-PSO) method is implemented to reduce ripple and oscillation with optimal Maximum Power Point (MPP) from PV. FL-PSO is a modification between Fuzzy Logic and Particle Swarm Optimization (PSO). PSO results are used as input from Fuzzy Logic. The addition of Fuzzy Logic after the PSO is to solve the problem of the value of duty cycle. So, the system can be more stable and have a fast response

\section{RESEARCH METHOD}

\subsection{Photovoltaic model}

In this case, several PV modules like Figure 1 are installed in parallel and in series form PV arrays to get high voltage and high current [16]. The current and voltage characteristics are generated from PV with ideal conditions (temperature $25^{\circ} \mathrm{C}$ and irradiance $1000 \mathrm{~W} / \mathrm{m}^{2}$ ) shown in Equation 1.

$$
I=I_{L}-I_{0}\left[\exp \left\{\frac{q\left(V+I \cdot R_{S}\right)}{n \cdot K \cdot T}\right\}-1\right]-\frac{V+I \cdot R_{S}}{R_{S H}}
$$

Where, $\mathrm{I}, \mathrm{I}_{\mathrm{L}}$ and $\mathrm{I}_{0}$ are output current, the current produced by photovoltaics and saturation current, respectively. $\mathrm{q}$ is element load, $\mathrm{V}$ is voltage between output terminals, $\mathrm{R}_{\mathrm{SH}}$ and $\mathrm{R}_{\mathrm{S}}$ are shunt resistance and series resistance, severally. $\mathrm{n}$ is ideal diode factor. Then, $\mathrm{K}$ is Boltzmann constant and $\mathrm{T}$ is temperature. Finally, $\mathrm{N}_{\mathrm{P}}$ and $\mathrm{N}_{\mathrm{S}}$ are the numbers of PV connected in parallel and series, respectively.

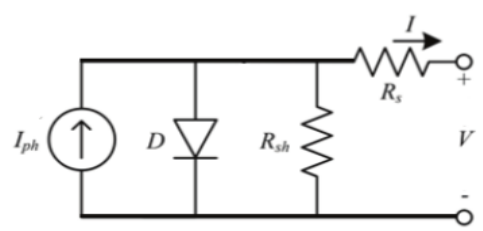

Figure 1 The equivalent circuit of PV

\subsection{Boost converter model}

The proposed boost converter is regulated by the high-frequency switch that controls the duty cycle to produce output voltage higher than the input voltage with the help of inductor and diode. like Figure 2[17,18].

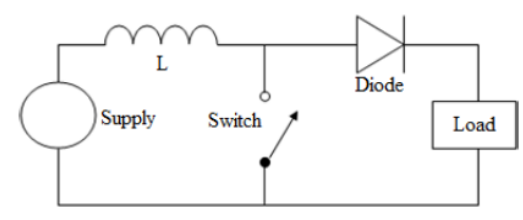

Figure 2 The equivalent circuit of boost converter [19]

\subsection{FL-PSO MPPT Algorithm}

PSO is one of the artificial intelligence designed from adopting the intelligence of bird and fish colonies[19]. Equation 2 and Equation 3 show standard formulations of PSO commonly used. Where, $v_{i}$ and $\mathrm{x}_{\mathrm{i}}$ are the particles velocity and the particles position, respectively. $\mathrm{c}_{1}$ and $\mathrm{c}_{2}$ are the constants of positive, $\mathrm{w}$ is the inertia weight which affects particle velocity. Then, $\varphi_{1}$ and $\varphi_{2}$ are random variables between 0 and 1 . Finally, $p_{i}$ and $p_{g}$ are duty cycles obtained from the particles best position and the populations best position[20].

$$
v_{i}(t+1)=w \cdot v_{i}(t)+c_{1} \varphi_{1}\left(p_{i}-x_{i}(t)\right)+c_{2} \varphi_{2}\left(p_{g}-x_{i}(t)\right)
$$




$$
x_{i}(t+1)=x_{i}(t)+v_{i}(t+1)
$$

The FL-PSO algorithm applied, in this case, is shown as follows:

- Initialization parameters of the PSO

- Update the particles velocity using Equation 2

- Update the particles position based on Equation 3

- Evaluation of the fitness value to update the value of $p_{i}$ and $p_{g}$

- Compare the value of each candidate $p_{i}$ to get the best $p_{i}$ value, then the best $p_{i}$ value compared with the $\mathrm{p}_{\mathrm{g}}$ value to get the best $\mathrm{p}_{\mathrm{g}}$ value

- After the $p_{g}$ is obtained, the $p_{g}$ value is entered into the Fuzzy Logic which contains the membership function as shown in Figure 3.

- If the best $\mathrm{p}_{\mathrm{g}}$ value is not obtained, then return to step 2

- $\quad$ Repeat the iteration until it reaches the limit to get $\mathrm{p}_{\mathrm{g}}$ with the highest Maximum Power Point (MPP) or the best value.

The implemented Fuzzy Logic control the duty cycle of the boost converter like Figure 3 and Table $1[21,22]$. After $p_{g}$ is obtained, the best $p_{g}$ value is made as input from Fuzzy Logic. There is one input and one output that resulted from the Fuzzy Logic.

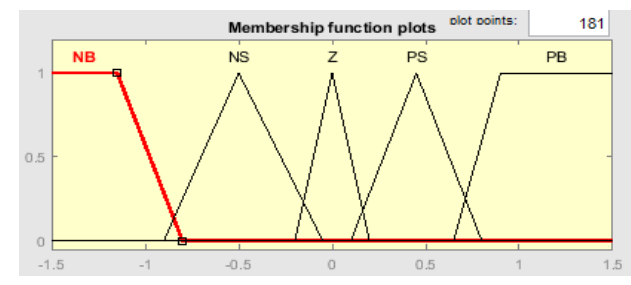

Figure 3 The membership function

Table 1 The Fuzzy Rule Base

\begin{tabular}{llllll}
\hline & NB & NS & ZE & PS & PB \\
\hline NB & ZE & ZE & PB & PB & PB \\
NS & ZE & ZE & PS & PS & PS \\
ZE & PS & ZE & ZE & ZE & NS \\
PS & NS & NS & NS & ZE & ZE \\
PB & NS & NB & NB & ZE & ZE \\
\hline
\end{tabular}

\section{RESULTS AND DISCUSSION}

Figure 4 is PV system which has the PV array, boost converter, MPPT, and load. The duty cycle of the boost converter is controlled by FL-PSO to increase the output voltage, minimize oscillation and reach the Maximum Power Point (MPP). Figure 5 and 6 show the characteristics of the PV module with an irradiance level of $1000 \mathrm{~W} / \mathrm{m}^{2}$ and a temperature of $25^{\circ} \mathrm{C}[23]$. The parameters used in this paper are four populations and one dimension. The symbols $w, c_{1}$, and $c_{2}$ are $0.4,1.2$ and 2 , respectively.

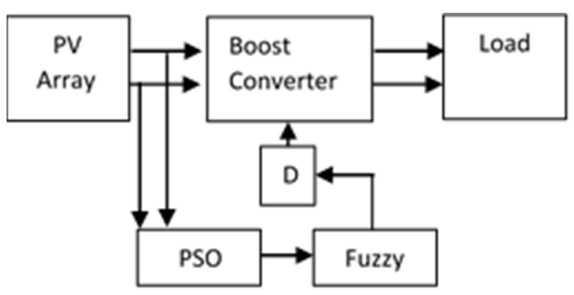

Figure 4. The Block diagram of PV system 


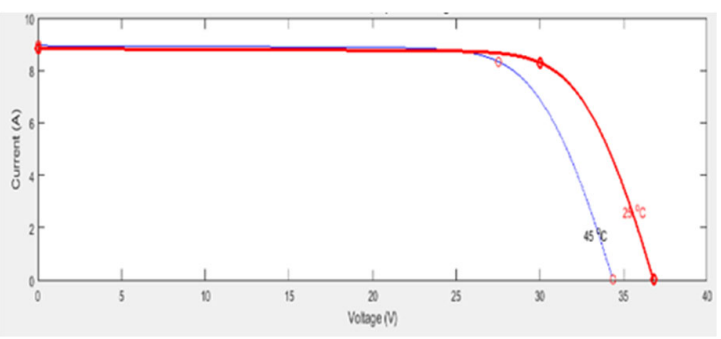

Figure 5. The PV I-V characteristics [24]

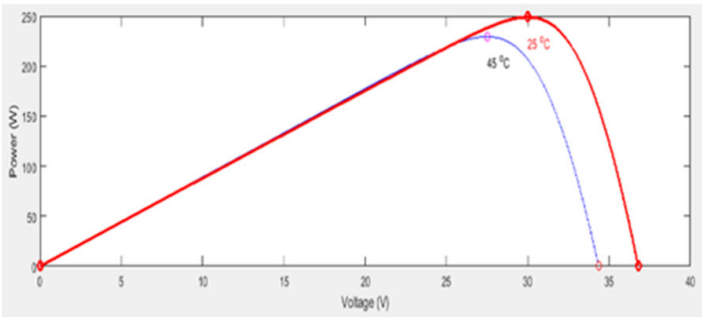

Figure 6. The PV P-V characteristics [25]

From the simulation using FL-PSO, the power of PV is $637.65 \mathrm{~W}$ and the power ripple is $69.5 \mathrm{~W}$ like Figure 7. In Figure 8, the voltage generated by the PV is 91.8 V. Figure 9, Figure 10 and Figure 11 are the duty cycle, voltage and power from the boost converter using FL-PSO, respectively. The voltage and power from the boost converter are $183.6 \mathrm{~V}$, and $637.7 \mathrm{~W}$. Stable conditions are reached within $0.354 \mathrm{~s}$ like Figure 11 .

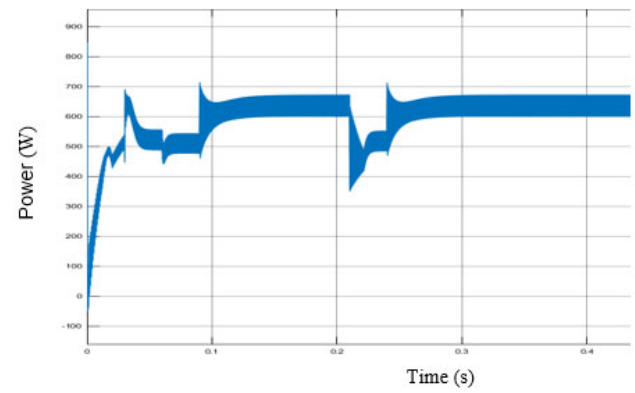

Figure 7. The power of PV using FL-PSO

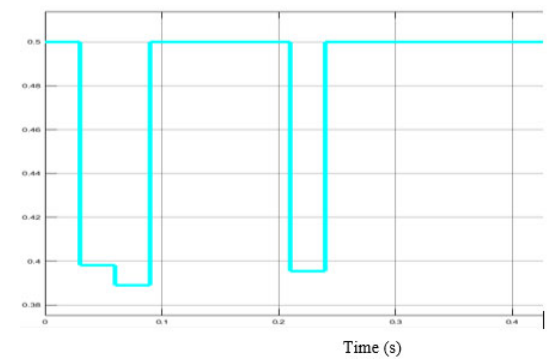

Figure 9. The duty cycle using FL-PSO

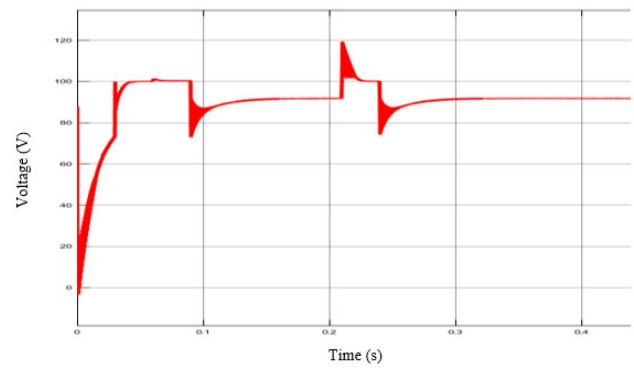

Figure 8. The voltage of PV using FL-PSO

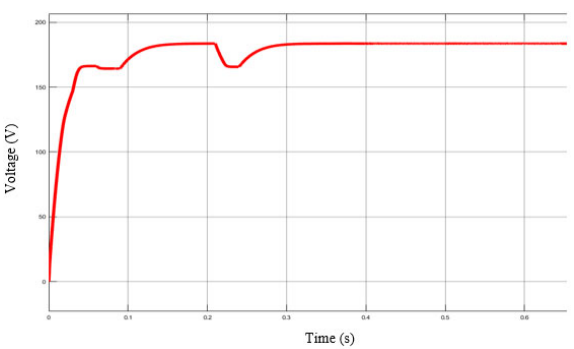

Figure 10. The voltage of the boost converter using FL-PSO 


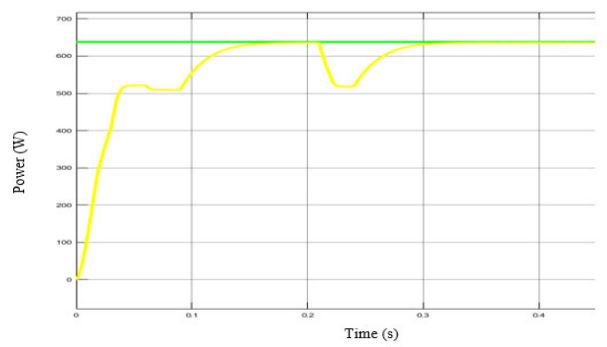

Figure 11 The boost converter power using FL-PSO

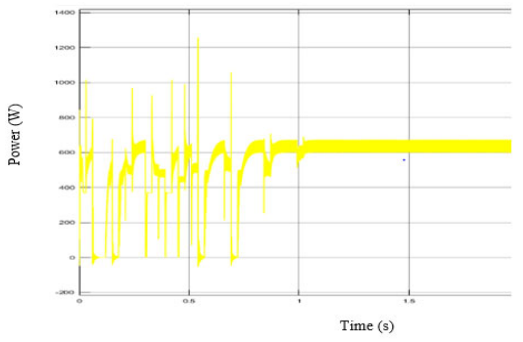

Figure 12. The power of PV using PSO

From the simulation based on PSO in Figure 12, the power of PV is $635.3 \mathrm{~W}$ and the power ripple is $72.2 \mathrm{~W}$. The voltage generated by PV is $91.77 \mathrm{~V}$ like Figure 13. Figure 14, Figure 15, and Figure 16 are are the duty cycle, voltage and power from the boost converter based on PSO, respectively. The voltage value of the boost converter is $183.6 \mathrm{~V}$. The power from the boost converter is $637.7 \mathrm{~W}$ and Stable conditions are reached within $1.085 \mathrm{~s}$ as shown in Figure 16.

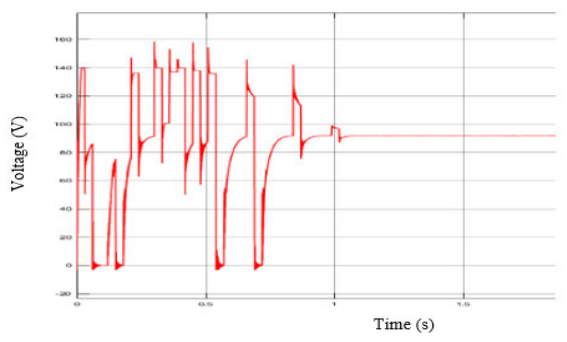

Figure 13. The voltage of PV using PSO

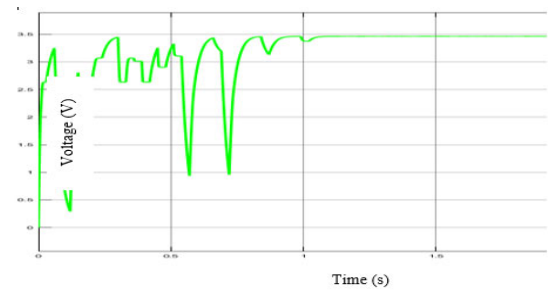

Figure 15. The voltage of the boost converter using PSO

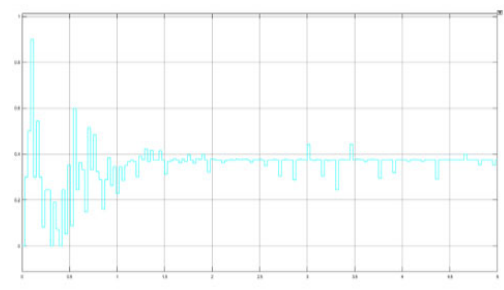

Time (s)

Figure 14. The duty cycle using PSO

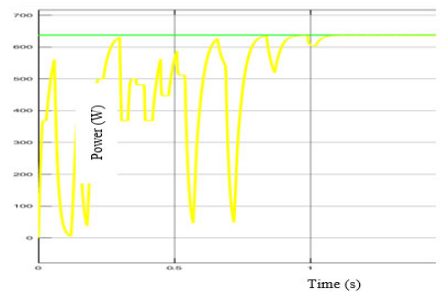

Figure 16. The power of the boost converter using PSO

To compare the performance of FL-PSO, this PV system is also simulated with a standard PSO. Different results are obtained from FL-PSO and PSO. The average output power of PV with FL-PSO is greater than PSO of $2.35 \mathrm{~W}$. Ripple output power of PV with FL-PSO is smaller than PSO of 2.7 W. The output voltage of PV with FL-PSO and PSO is $91.8 \mathrm{~V}$ and $91.77 \mathrm{~V}$, respectively. Finally, FL-PSO is faster and more stable than PSO because FL-PSO reaches MPP at $0.354 \mathrm{~s}$. The results of the duty cycle with FLPSO logic are more stable than PSO as shown in Figure 9 and Figure 14.

\section{CONCLUSION}

The MPPT technique is successfully executed by FL-PSO by its faster reaching MPP, a more stable system, and smaller oscillation the output power of PV. The output power ripple of PV is reduced to $2.7 \mathrm{~W}$ while the average output power is $2.35 \mathrm{~W}$. FL-PSO touches MPP faster at $0.354 \mathrm{~s}$. The reduced oscillation before reaching steady state results in a more stable system.

Int J Pow Elec \& Dri Syst, Vol. 11, No. 2, June 2020 : $1082-1087$ 


\section{REFERENCES}

[1] B. Subudhi, et al., "A comparative study on maximum power point tracking techniques for photovoltaic power systems," IEEE Trans. Sustain. Energy, vol. 4, no. 1, pp. 89-98, Jan. 2013.

[2] Suyanto, et al., "Design and Simulation of Neural Network Predictive Controller Pitch-Angle in Permanent Magnetic Synchronous Generator Wind Turbine Variable Pitch System," 1st International Conference on Information Technology, Computer and Electrical Engineering (ICITACEE), vol. 1, pp. 345-349, 2014.

[3] Scarpa V, et al., "Low complexity MPPT technique exploiting the effect of the PV cell series resistance," IEEE Applied Power Electronics Conference and Exhibition, pp. 1958-1964, Feb. 2008.

[4] D.V.N. Ananth, et al., "Flux Based Sensorless Speed Sensing and Real and Reactive Power Flow Control with Look-up Table based Maximum Power Point Tracking Technique for Grid Connected Doubly Fed Induction Generator," Indonesian Journal of Electrical Engineering and Informatics, vol. 3, no. 4, pp. 239-260, Dec. 2015.

[5] K. S. Tey, et al., "Modified incremental conductance MPPT algorithm to mitigate inaccurate responses under fast changing solar irradiation level," Solar Energy, vol. 101, pp. 333-342, Jan. 2014.

[6] Sathish Kumar Kollimalla, et al., "Variable Perturbation Size Adaptive P\&O MPPT Algorithm for Sudden Changes in Irradiance," IEEE Trans. Sustain. Energy, vol. 5, no. 4, pp. 718-728, July 2014.

[7] M. A. Elgendy, et al., "Operating characteristics of the $\mathrm{P} \& \mathrm{O}$ algorithm at high perturbation frequencies for standalone PV systems," IEEE Trans. Energy Convers., vol. 30, no. 1, pp. 189-198, Jun. 2015.

[8] Jusoh A, et al., "MPPT for PV System Based on Variable Step Size Perturb and Observe Algorithm," TELKOMNIKA Telecommunication Computing Electronics Control, vol. 15, no. 1, pp. 79-92, March 2017.

[9] S. B. Kjaer, "Evaluation of the hill climbing and the incremental conductance maximum power point trackers for photovoltaic power systems," IEEE Trans. Energy Convers., vol. 27, no. 4, pp. 922-929, Dec. 2012.

[10] A. K. Rai, et al., "Simulation model of ANN based maximum power point tracking controller for solar PV system," Solar Energy Mater. Solar Cells, vol. 95, no. 2, pp. 773-778, Feb. 2011.

[11] Elobaid L., "Artificial neural network based maximum power point tracking technique for PV systems," IECON 2012-38 th ., pp. 937-942, Oct. 2012.

[12] B. Alajmi, et al., "Fuzzy logic control approach of a modified hill-climbing method for maximum power point in microgrid stand alone photovoltaic system," IEEE Trans. Power Electron., vol. 26, no. 4, pp. 1022-1030, Apr. 2011.

[13] K. Ishaque, et al., "An improved particle swarm optimization (PSO)-based MPPT for PV with reduced steady-state oscillation," IEEE Trans. Power Electron., vol. 27, no. 8, pp. 3627-3638, Aug. 2012.

[14] K. Sundareswaran, et al., "MPPT of PV systems under partial shading conditions through a colony of flashing fireflies," IEEE Trans. Energy Convers., vol. 29, no. 2, pp. 463-472, Jun. 2014.

[15] Satyajit Mohanty, et al., "A New MPPT Design Using Grey Wolf Optimization Technique for Photovoltaic System Under Partial Shading Conditions," IEEE Transactions on Sustainable Energy, vol. 7, no. 1, pp. 181-188, Jan. 2016.

[16] Ali Rahnamaei, et al., "A Novel Grid Connected Photovoltaic System,” Bulletin of Electrical Engineering and Informatics, vol. 5, no. 2, pp. 133-143, June. 2016.

[17] T. K. Soon, et al., "A fast converging MPPT technique for photovoltaic system under fast varying solar irradiation and load resistance," IEEE Trans. Ind. Informat., vol. 11, no. 1, pp. 176-186, Feb. 2015.

[18] Shilpa Sreekumar, et al., "Fuzzy Logic Controller Based Maximum Power Point Tracking of Photovoltaic System Using Boost Converter," 4th ICCCNT, July 4-6, 2013.

[19] K. Ishaque, et al., "A deterministic particle swarm optimization maximum power point tracker for photovoltaic system under partial shading condition," Industrial Electronics, IEEE Transactions, vol. 60, pp. 3195-3206, 2013.

[20] Aji Akbar Firdaus, et al., " Distribution Network Reconfiguration Using Binary Particle Swarm Optimization to Minimize Losses and Decrease Voltage Stability Index," Bulletin of Electrical Engineering and Informatics, vol. 7, no. 4, pp. 514-521, Dec. 2018.

[21] Zhanghong, et al., "MPPT control strategy for photovoltaic cells based on fuzzy control," 12th International Conference on Natural Computation, Fuzzy Systems and Knowledge Discovery (ICNC-FSKD), pp. 450-454, 13-15 Aug. 2016.

[22] Ahmad Saudi Samosir, et al., "Modeling and Simulation of Fuzzy Logic based Maximum Power Point Tracking (MPPT) for PV Application," International Journal of Electrical and Computer Engineering (IJECE), vol. 8, no. 3, pp. 1315-1323, June 2018.

[23] Mohammed Slimi, et al., "Maximum power control for photovoltaic system using intelligent strategies," International Journal of Electrical Power \& Energy Systems, vol. 10, no. 1, pp. 423-432, March 2019.

[24] Sobhan Dorahaki., " A Survey on Maximum Power Point Tracking Methods in Photovoltaic Power Systems," Bulletin of Electrical Engineering and Informatics, vol. 4, no. 3, pp. 169-175, Sept. 2015.

[25] Killi M, et al., "Modified perturb and observe MPPT algorithm for drift avoidance in photovoltaic systems," IEEE Transactions on Industrial Electronics, vol. 62, no. 9, pp. 5549-5559, 2015. 